\title{
O (INTER) DISCURSO DA POSSE DE LUIZ INÁCIO LULA DA SILVA (2002): PRODUÇÃO DE SENTIDO E FORMAÇõES DISCURSIVAS \\ THE (INTER) DISCOURSE IN LUIZ INÁCIO LULA DA SILVA'S INAUGURATION (2002): PRODUCTION OF SENSE AND DISCURSIVE FORMATIONS
}

Jaqueline de Jesus BEZERRA ${ }^{1}$

Ivaneide Gonçalves de BRITO²

Maria da Luz OLEGÁRIO3

daluzprof@gmail.com

\begin{abstract}
RESUMO. 0 presente artigo consiste em investigar de que forma os sentidos são produzidos pelo interdiscurso e pelas formações discursivas no enunciado político de posse do então presidente Luiz Inácio Lula da Silva (2002) à luz da Análise de Discurso Francesa. É uma pesquisa qualitativa, de natureza básica e de caráter descritivo. A abordagem teórica está pautada, primordialmente, nas discussões de Pêcheux $(1975)$ e Orlandi $(2009,2014)$ que, ao tratarem da análise de discurso, procuram verificar como um objeto simbólico produz sentidos e de que forma pode ser significado pelos sujeitos constituintes do e no discurso. Partindo do questionamento que norteia este estudo, é salutar destacar a importância das formações discursivas e do interdiscurso na estruturação de um enunciado político enquanto gênero do discurso, destacando as construções ideológicas presentes nele. Como resultado, pode-se atestar que, a partir da perspectiva discursiva, é possível produzir novos e diferentes sentidos no texto, sobretudo pela percepção da materialização da linguagem na história e pela manifestação da ideologia na língua. .0 sujeito eleito como presidente do Brasil, em 2002, evidencia, em seu discurso de posse, a partir das suas vivencias e memórias históricas, a construção das formações discursivas em vozes outras (interdiscurso ) de forma a evidenciar um sujeito inclusivo, companheiro e de irmandade com o povo, seu maior interlocutor.
\end{abstract}

PALAVRAS-CHAVE: Produção de sentido. Discurso político. Análise de Discurso.

ABSTRACT. The present article consists of investigating how the senses are produced by the interdiscourse and the discursive formations in the inaugural political utterance of the then President Luiz Inácio Lula da Silva (2002) in the light of the French Discourse Analysis. It is a qualitative research, of a basic nature and descriptive character. The theoretical approach is based primarily on Pêcheux's (1975) and Orlandi's discussions $(2009,2014)$, which, when dealing with discourse analysis, seek to verify how a symbolic object produces meanings and in what way it can be signified by the constituent subjects, both of and in the discourse. Starting from the questioning that guides this study, it is noteworthy to highlight the importance of the discursive formations and the interdiscourse in structuring a political utterance as genre of discourse, emphasizing the ideological constructions present in it. As a result, it can be stated that from the discursive perspective, it is possible to produce new and different meanings in the text, above all, by the perception of the language materialization in history and by the ideology manifestation in language.

. KEYWORDS: Meaning production. Political discourse. Discourse analysis.

\footnotetext{
${ }^{1}$ Mestre pelo PROFLETRAS-CFFP-UFCG; doutoranda em Letras pela Universidade Estadual do Rio Grande do Norte-UERN;

2 Mestre pelo PROFLETRAS-CFFP-UFCG e professora da Educação Básica da Rede Pública.

3 Doutora em Educação e Mestre em Língua Portuguesa. Docente do DHP-UFPB. Está vinculada ao PROFLETRAS-CFP-UFCG e ao Programa de Pós-Graduação nas Organizações Aprendentes -MPGOA-UFPB.
} 


\section{Considerações iniciais}

Analisar um texto na perspectiva discursiva significa ir além de uma leitura superficial e de uma investigação linguística, mas, sobretudo, analisar sua estrutura no plano do discurso, compreendendo os vieses ideológicos desenvolvidos nele. Alguns fatores fazem-se essenciais para tal atividade, como a definição da situação-problema norteadora da análise, os sujeitos presentes no/do discurso, as condições de produção que possibilitaram a constituição do texto, a temática tratada, dentre outros.

Nessa perspectiva, para constituir o corpus deste trabalho, indagamos que formações discursivas e que tipo de interdiscursividade estruturam o discurso político como gênero do discurso. A análise está fundamentada nos estudos de Pêcheux (1975) e de Orlandi $(2009,2014)$, que discorrem sobre a Análise do Discurso, enquanto proposta teórico-metodológica. Assim, propomo-nos a investigar quais construções ideológicas se consolidam no enunciado político a partir das formações e das memórias discursivas presentes.

Desse modo, tem como objetivo geral analisar de que forma os sentidos são construídos pelo interdiscurso e pelas formações discursivas num enunciado político, à luz da análise de discurso francesa. Os objetivos específicos estão assim dispostos: discutir sobre a concepção de interdiscurso e de formação discursiva; identificar os elementos que caracterizam interdiscurso e formação discursiva no enunciado político e perceber os efeitos de sentidos provocados pela ativação do interdiscurso e da formação discursiva nos enunciados que compõem o discurso do Presidente Luis Inácio da Silva, na ocasião de sua posse, em 2002.

O corpus definido para esta análise compõe-se de um enunciado político, particularmente, o primeiro discurso de posse do candidato à Presidência da República, em 2002, escolhido por se tratar do enunciado de um eleito esquerdista para presidente do país, após anos de governos de direita. Assim, decidimos investigar a ideologia presente no discurso do sujeito que, pretensamente, propõe-se a mudar, radicalmente, a forma de governo no Brasil.

Assumindo um caráter qualitativo, acreditamos ser de grande importância analisar os diversos gêneros numa perspectiva discursiva, visto o espaço alcançado pela Análise de Discurso nos últimos anos. A seguir, apresentaremos a contextualização 
teórica da AD de linha francesa, pautada, sobretudo, nos aspectos interdiscursivos e nas formações discursivas, apontando tais aspectos no enunciado político, como já dissemos.

\section{Do discurso, da história e da ideologia.}

Ao pensar em analisar um discurso, não há como não remeter a Michel Pêcheux (1969), o precursor da Análise de Discurso, doravante AD, na França, no século XX. Surgida por uma necessidade de estudiosos em significar a linguagem, a AD preocupa-se, de acordo com Orlandi (2009, p. 15), "em compreender a língua fazendo sentido", concebendo a linguagem como "mediação necessária entre o homem e a realidade natural e social". Nesse contexto, mediação assume o caráter de discurso e a AD passa a atuar, então, nas relações que os sujeitos estabelecem com a língua.

Em suma, a Análise de Discurso para Orlandi (2009, p. 15)

[...] como seu próprio nome indica, não trata da língua, não trata da gramática, embora todas essas coisas lhe interessem. Ela trata do discurso. E a palavra discurso, etimologicamente, tem em si a ideia de curso, de percurso, de correr por, de movimento. 0 discurso é assim palavra em movimento, prática de linguagem: com o estudo do discurso observa-se o homem falando.

Para o desenvolvimento dos estudos discursivos, foram consideradas três áreas do conhecimento que precisam dar conta da noção de discurso, da história, da ideologia e do social que caracterizaram o século XIX e que destoavam dos pressupostos da AD, a Linguística, o Marxismo e a Psicanálise. A Análise do Discurso constitui-se, portanto, na compreensão de que a língua não é tão somente estrutural, como preconizavam os estudos linguísticos, mas também, e principalmente, o acontecimento.

Além disso, para a $\mathrm{AD}$, o simbólico rompe com real, e o materialismo pregado pelas ideias marxistas perde espaço no campo discursivo. Igualmente, o sujeito do discurso é ideológico e tal ideologia associa-se ao inconsciente sem ser, contudo, absorvida por ele, destoando então dos postulados freudianos.

Nesse sentido, a Análise de Discurso procura verificar como um objeto simbólico produz sentidos, de que forma pode ser significado pelos sujeitos constituintes do e no discurso. Assim, é preciso considerar como sujeito do discurso aquele que fala, que enuncia, e como sujeito no discurso, aquele de quem se fala.

A produção de sentidos também é estabelecida pelo contexto de produção e pelos conhecimentos prévios dos sujeitos que, por sua vez, são acionados pelas chamadas, no contexto da $\mathrm{AD}$, memórias discursivas, às quais Orlandi (2009) concebeu como interdiscursividade. Memórias discursivas e interdiscurso são, pois, conhecimentos e 
conceitos arquivados em cada sujeito do discurso sobre determinados dizeres que se conectam com outros conhecimentos e conceitos para constituírem novos dizeres, entrecruzando-se com diferentes campos do saber e dando origem a outro importante elemento no desenvolvimento da Análise de Discurso, as formações discursivas.

Assim, é fulcral lembrar que um dizer é constituído a partir de um "já dito", de algo já enunciado, que nem sempre, porém, é percebido pelo enunciador. Nessa perspectiva, o sujeito do discurso é caracterizado por dois tipos de esquecimentos ideológicos, no que concerne Pêcheux (1975), também definidos de involuntários. 0 primeiro, de caráter parafrástico, reitera que todo dizer é construído a partir de um que já foi dito e que, enquanto sujeito, esquecemos completamente desse aspecto e enunciamos como se fosse algo inédito, criado e desenvolvido unicamente por nós, umas das feridas narcísicas enfrentadas pelo ser humano: este não é a fonte de seu próprio dizer, desbancado pela criação do inconsciente freudiano (GIDDENS, 1993). 0 segundo, por outro lado, é de efeito polissêmico, uma vez que aquilo é dito pode ser interpretado e compreendido de formas diferentes pelos diferentes sujeitos, a depender do contexto de recepção do enunciado e das memórias que serão acionadas pelos sujeitos a partir dos conhecimentos prévios que lhe constituem. Como afirma Fernandes (2017, p. 11), “o sujeito está inserido em uma conjuntura social, tomado em um lugar social, histórica e ideologicamente marcado [...]". E acrescenta que "assim, as noções de polifonia e heterogeneidade também constituem objeto de reflexão para se compreender o que chamamos de sujeito discursivo".

Tais esquecimentos, desse modo, são fundamentais para a produção de sentidos dos discursos e os dizeres, embora não tenham sido concebidos em nós, materializamse em nós e é esse fator que, para Orlandi (2009), torna-se responsável pela existência dos sujeitos e dos sentidos. Enquanto sujeitos da enunciação, estamos a todo tempo reproduzindo discursos já ditos por outros sujeitos, mas que pelo efeito do esquecimento ideológico, constituímos como se fossem nossos e damos-lhe uma significação que, ao atingir outro sujeito, pode ou não gerar uma significação diferente daquela pretendida pelo sujeito de enunciação.

Nesse contexto, para desenvolver o corpus desta pesquisa, utilizamo-nos de dois aspectos da Análise de Discurso responsáveis pela produção de sentidos, a formação discursiva e a interdiscursividade. A primeira está relacionada às direções assumidas pelo discurso na materialidade linguística; a última diz respeito às memórias discursivas a 
que o texto remete. Também consideraremos o intertexto como um aspecto interdiscursivo, ainda que ele não seja pautado pelo esquecimento ideológico, mas, pelo contrário, pela citação direta ou indireta a outros enunciados.

\section{Formações discursivas e interdiscursividade}

Segundo Orlandi (2014), a formação discursiva se define como aquilo que, numa dada formação ideológica, determina o que pode e deve ser dito. Assim, é pelo contexto que definimos o tipo de discurso que devemos assumir e, então, pela escolha discursiva é que atribuímos e produzimos sentidos nos diversos enunciados. Nesse contexto,

\footnotetext{
[...] podemos dizer que o sentido não existe em si, mas é determinado pelas posições ideológicas colocadas em jogo no processo sócio-histórico em que as palavras são produzidas. As palavras mudam de sentido segundo as posições daqueles que as empregam. (ORLANDI, 2014, p. 42-43).
}

Sob esse aspecto, é preciso considerar que, a depender do caráter do texto, seja religioso, político ou publicitário, o enunciador precisa fazer sua escolha discursiva, levando em conta as direções assumidas pelo texto. 0 analista do discurso, dessa forma, passará a atribuir sentido à escolha discursiva do enunciado, seguindo as formações desencadeadas nele.

No caso de um enunciado político, por exemplo, o analista precisa verificar quais são as formações discursivas assumidas pelo sujeito na constituição do texto para transformá-lo no gênero pretendido. Alguns questionamentos observados na superfície e/ou estrutura podem ser pertinentes, como: a linguagem empregada é persuasiva e sedutora? Os vocativos utilizados denotam proximidade à pessoa que fala? 0 público a que se dirige o discurso é colocado como protagonista dos fatos apresentados? Que relação se estabelece entre o sujeito que fala e o sujeito que é falado? E como questão central, o analista perceberá as formações discursivas e o interdiscurso constitutivos do sujeito que fala.

O interdiscurso, por sua vez, está relacionado às memórias discursivas acionadas na construção do enunciado. Na visão de Orlandi (2009, p. 31), a memória discursiva é o saber o que "torna possível todo dizer e que retorna sob a forma do pré-construído, o jádito que está na base do dizível, sustentando cada tomada da palavra". Nessa perspectiva, aquilo que dizemos já foi anteriormente dito e também já esquecido. Aqui entra o que definimos acima de esquecimento ideológico. Daí, as palavras que utilizamos só terão sentido se já fizerem sentido, a partir do contexto de enunciação. 
Orlandi (2009) alerta-nos para o fato de não confundirmos interdiscurso com intertexto. Enquanto o interdiscurso ocorre no campo imaterial, o intertexto que está na materialidade do enunciado é um aspecto da textualidade. 0 primeiro, para a autora, é da ordem do saber discursivo; já o segundo restringe-se à relação de um texto com outros textos, seja essa relação constituída por uma citação direta ou indireta.

Em suma, temos:

É preciso não confundir o que é interdiscurso e o que é intertexto. 0 interdiscurso é todo o conjunto de formulações feitas e já esquecidas que determinam o que dizemos. Para que minhas palavras tenham sentido é preciso que elas já façam sentido. E isto é efeito do interdiscurso: é preciso que o que foi dito por um sujeito específico, em um momento particular se apague na memória para que, passando para o "anonimato", possa fazer sentido em "minhas" palavras. (ORLANDI, 2009, p. 33-34).

No entanto, nesta análise, compreenderemos o intertexto como um critério discursivo porque, a nosso ver, ainda que ocorra na materialidade do texto, remonta a memórias que são acionadas e interligadas para dar sentido ao enunciado. Assim, não pretendemos excluir os postulados de Pêcheux (1975), tampouco os estudos orlandianos, ao colocar intertexto e interdiscurso numa posição lado a lado no campo da $\mathrm{AD}$, mas, sobretudo, acrescentar que a intertextualidade também ocorre pela formação de memórias.

As formações discursivas e a interdiscursividade, portanto, são vieses bastante significativos na Análise de Discurso de linha francesa e, nesta pesquisa, enveredarão nossa investigação, abrindo espaço, também, para o intertexto. Uma análise apenas linguística de um enunciado pode ser bastante superficial, se ignorados os aspectos discursivos. Apropriar-se do discurso, então, permite ultrapassar a superficialidade de uma primeira leitura do texto ou de uma análise meramente gramatical.

\section{Aspectos Metodológicos}

A abordagem desenvolvida nesta pesquisa é de caráter qualitativo, visto que não é possível quantificar os aspectos analisados e preocupa-se em compreender e interpretar determinados comportamentos, no caso, adotados pelo sujeito de um texto, constituindo um "discurso político". A natureza da análise é básica, por não ter aplicação prática, e tem um objetivo descritivo, considerando-se que serão descritos aspectos e eventos de um determinado discurso, típico da $\mathrm{AD}$.

O corpus utilizado foi o discurso político do ex-presidente Luiz Inácio Lula da Silva, quando de sua posse em 2002, coletado no site do jornal Folha de São Paulo e 
publicado em 27 de outubro de 2002. A escolha se deu pela importância política dada às eleições presidenciais cujo candidato era visto pela sociedade, sobretudo pelas classes populares, como a grande esperança de uma administração que diminuísse o fosso social brasileiro. Além disso, em sua grande maioria, há um forte processo de identificação entre os sujeitos trabalhadores de baixa renda, com um presidente eleito de similar origem, condição divulgada e explorada no período da Campanha Eleitoral, cujo resultado final foi de 61,27\% (FOLHA DE SÃO PAULO, 2002). Outra justificativa é que "nenhuma eleição brasileira gerou tamanha quantidade de pesquisas como a disputa pela Presidência da República em 2002" (FIGUEIREDO; COUTINHO, 2003). As condições de produção, portanto, são evidentes do ponto de vista político e ideológico.

A seguir, podemos perceber que as formações discursivas (FD) "não são definidas a priori como evidências ou lugares estabilizados, mas como regiões de confronto de sentidos" (ORLANDI, 2014, p. 13). Propomos, portanto, investigar neste discurso a produção de sentidos no tocante às condições de produção de tal discurso, isto é, um discurso de posse de um político eleito e aclamado pelo povo.

\section{Análise e discussão dos dados}

Retomando a concepção de formação discursiva, segundo Orlandi (2009, 2014), reiteramos que significa aquilo que costumamos dizer e que podemos dizer, num dado contexto, se as condições em que o enunciado foi produzido permitirem. Assim, no âmbito científico, há uma formação discursiva específica e, de certa forma, habitual, da mesma forma que há no âmbito político ou em qualquer outro.

Analisando o discurso eleito na perspectiva da $\mathrm{AD}$ e reiterando que se trata de um enunciado político, encontramos as seguintes formações discursivas: o agradecimento como uma forma de reconhecer os préstimos do outro que o confiou e, por essa razão, elegeu-o, sendo uma das formações discursivas mais comuns desse tipo de texto, como se vê nas passagens abaixo:

- Eu queria agradecer e cumprimentar o comportamento das autoridades que cuidaram do processo eleitoral, pelo Tribunal Superior Eleitoral e o seu presidente [...]. Meus agradecimentos ao presidente Fernando Henrique Cardoso [...].

- Quero agradecer aos milhões e milhões de homens, mulheres e adolescentes que votaram em mim e no companheiro José Alencar e agradecer aos milhões $e$ milhões de homens, mulheres e adolescentes que votaram no meu adversário, que se abstiveram de votar, [...].

- Eu quero aqui agradecer à minha companheira Benedita da Silva. [...].

- Por último, eu quero agradecer essa extraordinária figura. [...] acho que esse companheiro aqui não foi a única, mas foi uma das coisas mais extraordinárias 
que aconteceram nessa campanha de 2002. Zé Alencar e eu não vamos ser um presidente e um vice [...].

- Quero agradecer do fundo da minha alma a todos os companheiros que no primeiro turno e no segundo turno trabalharam de forma incansável. Quero agradecer à direção do meu partido e à direção dos partidos aliados. (LULA, 2002).

Percebe-se que são muitos os agradecimentos do candidato a vários sujeitos envolvidos no processo eleitoral. Nesse caso, para um candidato, a gratidão é fundamental, é preciso agradecer aos responsáveis, direta ou indiretamente pela vitória, caso contrário, poderá ser criticado e julgado ingrato, o que é negativo para o sujeito político. 0 agradecimento é, então, algo que deve ser dito e enfatizado em um discurso político. (Mais do que isso, o discurso do Presidente eleito é includente: das autoridades mais altas na hierarquia institucional eleitoral (Tribunal Superior Eleitoral) ao seu adversário político Fernando Henrique Cardoso, ex-presidente brasileiro). Em seguida, evidencia, dá ênfase, igualmente, a homens e mulheres (sem fazer distinção de gênero). Agradece aos dois gêneros, sem fazer distinção geracional, quando ressalta seu agradecimento aos jovens. Na sequência, agradece ao vice José Alencar, cuja adjetivação é "essa extraordinária figura". Expressa ainda que não haverá hierarquia entre a presidência e a vice-presidência pela confiança depositada na figura do vice-presidente. Ainda, agradece a todos os companheiros "do fundo" de sua alma e, finalmente, aos companheiros dos partidos. Na materialidade linguística, os agradecimentos do sujeito incluem todos/os sem hierarquização seja política, seja de gênero, seja de geração.

Pode-se analisar outra formação que se destaca que é a menção ao adversário, como é feita neste trecho:

"Meus agradecimentos ao presidente Fernando Henrique Cardoso pelo fato de ter anunciado à sociedade brasileira que possivelmente tenhamos a mais sensata e a mais democrática transição já vista no nosso país. [...]. Já conversei com meu adversário, José Serra, recebi um telefonema dele agora pouco.".

É perceptível aqui que o adversário mostrou ao povo que a melhor solução, na situação de derrota, seria a aceitação da vitória do outro, optando pela transição passiva de governos. Numa eleição em que os candidatos prezam pela ética e pela boa postura, é bastante comum os políticos mencionarem a oposição na intenção de se sobressaírem. 
Uma terceira formação discursiva é observada na tentativa de o candidato eleito animar outros candidatos derrotados de sua base partidária, na disputa de outros cargos. É o que podemos observar no trecho:

\begin{abstract}
- Quero dizer ao meu querido companheiro Genoino que você não perdeu a eleição, porque você não era governador, você apenas deixou de ganhar.

- Mas você vai perceber, meu companheiro Genoino, que, se você souber tirar proveito, uma derrota vai te deixar muito mais maduro, muito mais preparado e muito mais perto da próxima vitória. Para quem veio de Quixeramobim, ter 40 e poucos porcento de votos em São Paulo. Você, Genoino, foi um dos candidatos mais brilhantes que eu conheci. Se todo mundo tivesse o seu bom humor e a sua vontade, meu caro, o Brasil seria infinitamente melhor. (LULA, 2002).
\end{abstract}

$\mathrm{Na}$ tentativa de fortalecer o outro candidato derrotado de sua base partidária, o eleito superestima suas qualidades, diminuindo o impacto da derrota. É um jogo discursivo bastante comum no meio político e que funciona para externar a lamentação pela perda do outro, sem assumir, de fato, que se trata de uma perda, visto o impacto negativo causado pela palavra.

Outra formação discursiva do discurso político é a menção aos problemas deixados pela gestão anterior e a promessa de construção de um país/estado/cidade melhor, com a participação de toda a população, procurando assim, convencer o povo de que fez a escolha certa, pois ele não será esquecido, pelo contrário, governará junto com os representantes. Essa formação discursiva pode ser vista neste fragmento:

- Queria dizer para vocês que a responsabilidade de governar é muito grande. Eu e minha equipe iremos governar esse país, mas não seria exagero dizer pra vocês que apenas um presidente, o seu vice e a nossa equipe não será suficiente para que a gente governe o Brasil com os seus problemas, portanto nós vamos convocar toda a sociedade brasileira, todos os homens e mulheres de bem desse país, todos os empresários, todos os sindicalistas, todos os intelectuais, todos os trabalhadores rurais, toda a sociedade brasileira, enfim, para que a gente possa construir um país mais justo, mais fraterno e mais solidário. (LULA, 2002).

Junto com a promessa de construção de um país melhor, vem a promessa de paz e esperança, subentendendo-se que esses sentimentos não existiam antes e passarão a existir no novo governo: "[...] eu quero dizer pra vocês que o Brasil está mudando em paz. E, mais importante, a esperança venceu o medo."

Exaltar a imagem do povo, colocando-o como de extrema importância para o processo eleitoral, com a finalidade de mostrar que o político reconhece a sua importância na eleição vitoriosa é outra formação discursiva desse tipo de enunciado, como podemos perceber em 
- Primeiro, eu quero dar parabéns ao povo brasileiro pelo extraordinário espetáculo de democracia que ele deu no dia 27 de outubro de 2002, escolhendo o seu presidente da República e seus governadores. [...].

- Quero agradecer aos milhões e milhões de homens, mulheres e adolescentes que votaram em mim e no companheiro José Alencar [...].

- [...], nós vamos convocar toda a sociedade brasileira, todos os homens e mulheres de bem desse país, todos os empresários, todo os sindicalistas, todos os intelectuais, todos os trabalhadores rurais, toda a sociedade brasileira, enfim, para que a gente possa construir um país mais justo, mais fraterno e mais solidário [...]. (LULA, 2002).

Além das principais formações discursivas elencadas acima e que são comuns a qualquer discurso político, percebe-se ainda, no enunciado ora analisado, a interdiscursividade, também responsável pela produção de sentidos.

Nesse caso, o interdiscurso "é definido como aquilo que fala antes, em outro lugar, independentemente. Ou seja, é o que chamamos memória discursiva" (ORLANDI, 2009, p. 31). O nosso propósito é resgatar as memórias presentes no discurso político em análise e os traços interdiscursivos que, quer queira ou não, remetem a outras memórias já ditas anteriormente.

Assim, alguns aspectos interdiscursivos podem ser percebidos no corpus desta pesquisa, como observados em:

Eu quero aproveitar e dizer aqui para vocês que o que mais me incentivou a convencer a Benedita a assumir o governo do Rio foi o fato de ela ser negra. E ela assumir o governo do Rio de Janeiro foi a maior conquista dos negros depois da libertação dos escravos neste país. (LULA, 2002).

No contexto acima, fica pressuposto que uma pessoa de cor negra tem poucas conquistas em vida e que a cor escura da pele é associada à escravidão que ocorreu nos primeiros séculos da colonização brasileira. Sendo, por essa razão, vítima de exclusão social e de outros inúmeros preconceitos, o que faz, diante da conquista de chegar a um cargo de cunho político, fator de destaque e de exaltação popular.

$O$ interdiscurso se apresenta também na passagem: " $E$, mais importante, a esperança venceu o medo. E hoje eu posso dizer para vocês que o Brasil votou sem medo de ser feliz.". Isso implica que, ao votar, as pessoas sentem medo, seja de escolher um candidato errado, seja por outra razão, e que a escolha do candidato vitorioso foi acertada, por isso uma escolha feliz. Além disso, o país depositava no eleito a esperança de mudança, para indicar insatisfação com o governo anterior.

Outro tipo de interdiscursividade está presente no trecho:

E vocês sabem que, quando eu falo companheiro, falo companheiro com uma coisa muito forte no coração, porque nem todo irmão é um grande companheiro, 
mas todo companheiro é um grande irmão. E você é um grande companheiro, meu querido Zé Alencar. (LULA, 2002).

Observa-se que, embora o fragmento caracterize-se por intertexto, é conveniente destacá-lo como um aspecto da interdiscursividade. Assim, o sujeito do discurso, ao afirmar que todo companheiro é um grande irmão faz alusão ao texto bíblico que diz que há amigos mais chegados que um irmão (PROVÉRBIOS 18:24). A memória discursiva diante dessa construção materializada no texto traz o discurso da Bíblia Sagrada, aglomerando em torno de si a família e seus valores socialmente valorizados.

Outro aspecto interdiscursivo concebido no texto em análise está no fragmento "Quero dizer que sem vocês eu não seria o Lulinha paz e amor dessa campanha.". 0 candidato eleito, durante a campanha, cria um slogan que ressalta a emoção em detrimento do conteúdo, por saber que, dessa forma, é mais fácil atingir às pessoas, persuadindo-as ao voto, subjetivando as eleições. Ademais, o governo anterior ou o candidato da oposição poderia privilegiar um discurso voltado para o trabalho, para a questão racional do ser humano.

Assim, analisar discursivamente um enunciado significa compreender as construções ideológicas presentes nele, que são diretamente influenciadas pelo contexto político-social em que seu autor está inserido, é o que a Análise de Discurso chama de condições de produção. No corpus analisado, vimos que o enunciador, para estruturar seu texto, utilizou-se de diferentes formações discursivas presentes no discurso político. Ainda empregou o interdiscurso e o intertexto com o fim de persuadir o sujeito leitor/ouvinte, corroborando todo o seu discurso eleitoral. As condições de produção não poderiam ser as mais profícuas para se utilizar das estratégias discursivas utilizadas.

\section{Considerações finais}

Todo discurso é dotado de intencionalidades e sentidos que, muitas vezes, para serem desvendados, é necessária uma análise mais aprofundada. Assim, para que se desvendem os sentidos de um discurso, é importante compreender suas condições de produção, quem é o sujeito desse e nesse discurso, que formações discursivas são inerentes àquele tipo de discurso, com quais outros se percebem relações.

A partir da análise do discurso político escolhido, realizada à luz da $\mathrm{AD}$ francesa, pôde-se perceber o quanto as formações discursivas e a interdiscursividade contribuem para a produção de sentidos num determinado contexto discursivo. 
Atingido o objetivo de analisar o discurso político, discutindo as concepções de formação discursiva e interdiscurso, compreendendo que enunciados são comuns e permitidos no âmbito político, que memórias discursivas são acionadas a partir daquele discurso, e identificando esses aspectos no corpus analisado, concluímos que foram vários e distintos os efeitos de sentido produzidos, os quais contribuem para uma compreensão efetiva da intencionalidade desse discurso.

Por fim, foi possível perceber a partir do enunciado analisado, quais as construções ideológicas explicitadas pelo sujeito eleito como presidente do Brasil, e quais vivências e memórias históricas foram ativadas e materializadas nesse discurso para a produção dos sentidos e para a manifestação da intencionalidade adotada pelo sujeito de acordo com as condições de produção.

\section{Referências}

GERHARDT, T. E.; SILVEIRA, D. T. (Orgs.). Métodos de pesquisa. Porto Alegre: Editora da UFRGS, 2009.

GIDDENS, Anthony. A transformação da intimidade: sexualidade, amor e erotismo nas sociedades modernas. São Paulo: UNESP, 1993.

FERNANDES, Cleudimar Alves. Análise do discurso: reflexões introdutórias. 4.ed. São Carlos: Claraluz, 2017.

FIGUEIREDO, Rubens; COUTINHO, Ciro. A eleição de 2002. Opin. Publica. vol.9 no.2 Campinas Oct. 2003.

FOLHA DE SÃO PAULO. 27 Out. 2002. (Versão online). Acesso em: 1 ago. 2017. http://www1.folha.uol.com.br

LULA DA SILVA, Luiz Inácio. "Íntegra do primeiro discurso de Lula como presidente eleito". Folha de São Paulo. 27 Out. 2002. (Versão online). Acesso em: 1 ago. 2017. http://www1.folha.uol.com.br

ORLANDI, Eni P. Análise de Discurso: princípios e procedimentos. 8. ed. Campinas: Pontes, 2009.

. Gestos de leitura: da história no discurso. (Org.). 4. ed. Campinas: Editora da Unicamp, 2014.

PÊCHEUX, M. Les Vérités de la Palice. Maspero: Paris, 1975. Trad. bras.: ORLANDI, E. et all. Semântica e discurso. Campinas: Editora da Unicamp.

Análise Automática do Discurso (AAD-69). In: GADET \& HAK (org). Por uma análise automática do discurso. Campinas: Ed. Unicamp, 1990, p.61- 162. 